\title{
Inferior Petrosal Sinus Thrombosis in a Child due to Malposition of Central Venous Catheter: A Case Report
}

\author{
Burcu Akıncı ${ }^{a}$ Muhterem Duyu ${ }^{b}$ Liya Alkılıçc Deniz Yılmaz Karapınara \\ Bülent Karapınar ${ }^{b}$ \\ ${ }^{a}$ Department of Pediatric Hematology, and ${ }^{b}$ Pediatric Intensive Care Unit, Faculty of Medicine, Ege University, and \\ 'Pediatric Intensive Care Unit, Şifa University Hospital, İzmir, Turkey
}

\section{Significance of the Study}

- In this case report, late diagnosis of malposition of the central venous catheter led to inferior petrosal sinus thrombosis. Hence, it is important to emphasize that postprocedure radiography should be performed to minimize complications, and possible complications should be monitored carefully if there is malpositioning of the catheter.

\section{Keywords}

Catheter interventions · Sinus thrombosis - Malposition

\section{Abstract}

Objective: To report a case of inferior petrosal sinus thrombosis associated with malposition of central venous catheterization (CVC). Clinical Presentation and Intervention: $A$ 5-month-old boy was admitted to Şifa University Hospital because of pneumonia. When exophthalmos occurred in the right eye, he was referred to Ege University Hospital. Cranial magnetic resonance imaging and magnetic resonance venography confirmed that the catheter in the right inferior petrosal sinus caused the thrombosis. The catheter was extracted and anticoagulant treatment was started. Conclusion: In this case report, malpositioning of the CVC was the

\section{KARGER}

E-Mail karger@karger.com www.karger.com/mpp

\section{(C) 2017 The Author(s) \\ Published by S. Karger AG, Basel \\ Karger \\ Open access}

This is an Open Access article licensed under the Creative Common Attribution-NonCommercial-4.0 International License (CC BY-NC) (http://www.karger.com/Services/OpenAccessLicense), applicable to the online version of the article only. Usage and distribution for commercial purposes requires written permission. cause of the thrombosis. To minimize such complications, catheterization should be done with the supervision of an expert and postprocedure radiography should also be performed.

(C) 2017 The Author(s)

Published by S. Karger AG, Basel

\section{Introduction}

Central venous catheterization (CVC) is an invasive procedure which is used commonly in intensive care units to administer fluids, total parenteral nutrition, drugs, and blood products. Also, CVC enables monitoring of hemodynamics by measuring central filling pressure and taking repeated blood samples. Although it is a relatively safe procedure, multiple complications such as 
infection, pneumothorax, hematoma, and thrombosis have been described [1]. Furthermore, one of the most serious mechanical complications of CVC is malpositioning [1]. Cerebral sinovenous thrombosis is a relatively rare event in the pediatric population, with an estimated incidence of approximately 1/100,000 [2]. The most important causal factors for cerebral sinovenous thrombosis are dehydration, infections, prothrombotic states, and chronic systemic diseases. Seizure, headache, and encephalopathy are the common presenting symptoms. Cerebral sinovenous thrombosis may be associated with serious neurological complications, lifelong morbidity, and even mortality [2]. Hence, we report a very rare case of accidental placement of a catheter in inferior petrosal sinus which caused thrombosis.

\section{Case Report}

A 5-month-old boy presented with pneumonia to Şifa University Hospital and was admitted to the pediatric intensive care unit. He experienced generalized tonic-clonic seizures and anticonvulsant treatment was administered. He was monitored as he was intubated. When exophthalmos occurred in the right eye, he was referred to Ege University Hospital. On admission, his Glasgow coma scale was $3 / 15$. Physical examination revealed exophthalmos, edema, and subconjunctival hemorrhage in the right eye. Also, there was bloody discharge from the eye (Fig. 1).

He had a central venous catheter which had been placed from the right subclavian vein at Şifa University Hospital. The anteroposterior chest X-ray revealed pulmonary infiltrate and also the abnormal location of the catheter (Fig. 2a). Cranial magnetic resonance (MR) imaging confirmed that the catheter was in fact in the right inferior petrosal sinus. Flair sequence on T2 revealed the presence of a hyperintense lesion on the left parieto-occipital regions, suggesting subacute ischemia. Also, there was diffusion restriction on diffusion-weighted sequences and enhancement of the pathologic area after injection of contrast. Cranial MR venography demonstrated stasis and occlusion in the right inferior petrosal sinus while the cranial MR angiography was normal (Fig. 2b).

The blood count, coagulometer readings, and prothrombotic markers such as protein C, protein S, antithrombin III, factor VIII, factor IX, lipoprotein (a), homocysteine, anticardiolipin, and lupus anticoagulant levels were determined to be normal. The patient was also evaluated for hereditary thrombophilic mutations such as prothrombin 20210G, factor V Leiden, and methylenetetrahydrofolate reductase, and no mutation was found.

He was diagnosed with inferior petrosal sinus thrombosis and anticoagulated with low-molecular-weight heparin at a dose 100 $\mathrm{IU} / \mathrm{kg} /$ dose twice daily. His catheter was removed. The anti-factor Xa level during the treatment ranged from 0.5 to 0.9 units $/ \mathrm{mL}$.

One week later, pneumonia was disrupted and he was extubated. His consciousness returned to normal. Also, his eye symptoms started to improve gradually and recovered fully on the 12th day. Ten days later, heparin supplementation was reduced at a dose

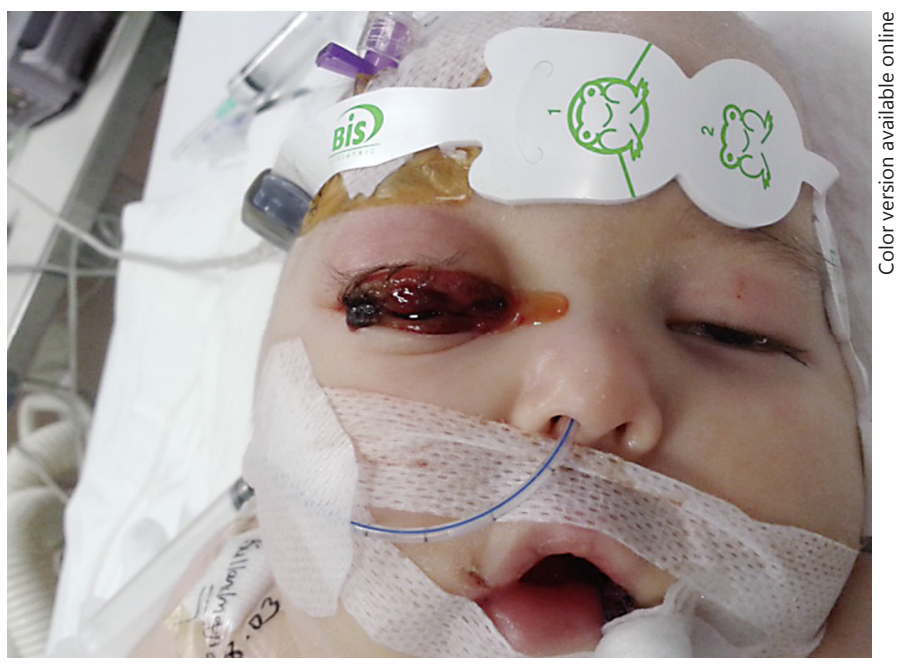

Fig. 1. Exophthalmos, edema, subconjunctival hemorrhage, and bloody discharge in the right eye (family permission of the photograph of the child was given).
Fig. 2. Abnormal location of the catheter (a) and hyperintense lesion (b) on cranial magnetic resonance imaging.
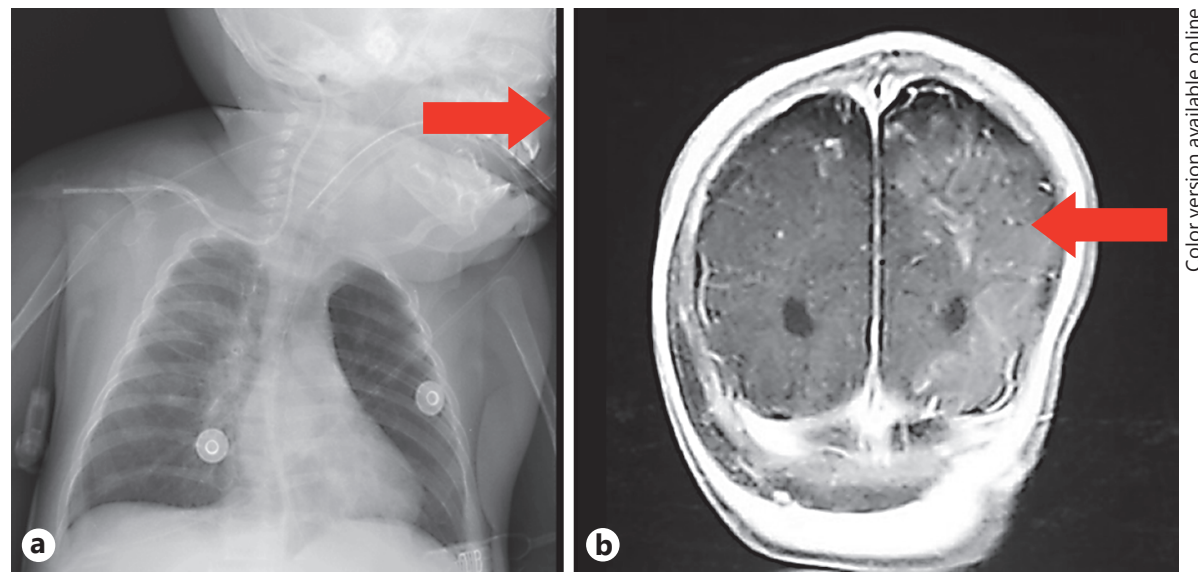
of once daily. He was discharged from the hospital on the 15th day. The low-molecular-weight heparin was continued for 3 months. Cranial MR venography taken in the third month of treatment did not show any thrombi at inferior petrosal sinus and after that heparin supplementation was stopped. The patient is still being followed up without any problems.

\section{Discussion}

In this report, the patient developed inferior petrosal sinus thrombosis due to malposition of the central venous catheter that led to inferior petrosal sinus thrombosis. Hence, superior and inferior ophthalmic veins and also inferior petrosal sinus drained into the cavernous sinus; probably the thrombosis in inferior petrosal sinus progressed to the cavernous sinus that was not shown on MRI.

Thrombosis is one of the most important complications of CVC, and catheter-related thrombosis risk increases with malpositioning. Pathogenic mechanisms of catheter-related thrombosis include the intravascular presence of a foreign surface, obstruction of venous flow, trauma to the venous wall, and endothelial irritation by the line. Dehydration, infection, polycythemia, cancer, trauma, and other genetic prothrombotic factors can facilitate the occurrence of thrombosis $[3,4]$. Nowak et al. [5] reported the association between catheter-related thrombosis and hereditary causes of thrombophilia in children. Sabzi and Faraji [6] described a case of a 38-year- old male who developed cerebral vein thrombosis after coronary artery bypass related to malpositioning of the subclavian central catheter into the internal jugular vein. Then the patient was diagnosed with protein $\mathrm{C}$ and $\mathrm{S}$ deficiency. In the current case, no predisposing risk factors other than the malposition of catheter could be found. It is advised that the placing of the tip of the catheter should be confirmed with diagnostic imaging, and anteroposterior chest radiography remains an important ancillary tool for verifying the location of the catheter tip [7]. If there is malpositioning of the CVC, the catheter should be removed or replaced as the first option. However, if the catheter must be used because of difficult venous access, the patient should be monitored for complications of malpositioning very closely.

\section{Conclusion}

In this case report, the patient developed inferior petrosal sinus thrombosis due to malpositioning of the central venous catheter. To minimize serious complications, postprocedure radiography should be performed and the placing of the tip of the catheter should be confirmed.

\section{Disclosure Statement}

The authors report no conflicts of interest.

\section{References}

1 Hedlung CL: Cerebral sinovenous thrombosis in pediatric practice. Pediatr Radiol 2013; 43:173-188.

2 Bhatt S, Dahat A, Jain N, et al: Indications and complications of central venous catheterization in critically ill children in intensive care unit. Natl J Med Res 2012;2:85-88.

3 Roldan CJ, Paniagua L: Central venous catheter intravascular malpositioning: causes, prevention, diagnosis, and correction. West J Emerg Med 2015;16:658-664.
4 Male C, Chait P, Andrew M, et al: Central venous line-related thrombosis in children: association with central venous line location and insertion technique. Blood 2003;101: 4273-4278.

5 Nowak-Gött U, Dübbers A, Kececioğlu D, et al: Factor V Leiden, protein C, and protein (a) in catheter-related thrombosis in childhood: a prospective study. J Pediatr 1997;131:608612.
6 Sabzi F, Faraji R: Cerebral vein thrombosis post CABG precipitated by malposition of subclavian central catheter in protein C \& $\mathrm{S}$ deficiency patient. Ethiop J Health Sci 2015; 25:283-288.

7 Venugopal AN, Koshy RC, Koshy SM: Role of chest X-ray in citing central venous catheter tip: a few case reports with a brief review of the literature. J Anaesthesiol Clin Pharmacol 2013;29:397-400. 